\title{
To What Extent the Hand Hygiene among Health Care Workers Become the Core of Best Practice in the COVID-19 Era?
}

\author{
Sultan Mohammed Al Mutairi, MPH ${ }^{1}$, Azzam Alotaibi, PhD', Mostafa Kofi, PhD ${ }^{1,2}$, Anas Alsuraimi, \\ $M D^{3}$ and Amen Bawazir, PhD ${ }^{*}$
}

\begin{abstract}
${ }^{1}$ Family and Community Medicine, Prince Sultan Medical Military City, Riyadh, Saudi Arabia
${ }^{2}$ Public Health and Occupational Medicine Department, Faculty of Medicine, Suez Canal University, Egypt ${ }^{3}$ College of Medicine, Alfasial University, Riyadh, Saudi Arabia

${ }^{4}$ Community and Environmental Department, College of Public Health and Health Informatics, King Saud Bin Abdulaziz University for Health Sciences, Riyadh, Saudi Arabia
\end{abstract}

*Corresponding author: Professor Amen Bawazir, MD, Dr. Epid, PhD, Department of Community and Environmental Health, College of Public Health and Health Informatics, King Saud Bin Abdulaziz University for Health Sciences, Prince Mutib Ibn Abdullah Ibn Abdulaziz, Ar Rimayah, Riyadh 14611, Saudi Arabia, Tel: +966-11-429-5422

\section{Abstract}

In the Era of COVID-19 outbreak, hand hygiene become a particularly critical for frontline healthcare workers (HCWs) who are overstretched and for whom this key routine task must be easy to complete and effective to prevent Healthcare-associated infections (HAls). Therefore, this current study aims to assess the level of knowledge, attitude and practice of hand hygiene among the HCWs and the potential factors influencing hand hygiene $(\mathrm{HH})$ compliance according to the hand hygiene protocols at primary health care $(\mathrm{PHC})$ centers in Prince Sultan Military Medical City (PSMMC), Riyadh, Saudi Arabia.

This cross-sectional study included clinical staff working at $\mathrm{PHC}$ centers. A pre-validate questionnaire was used with observational approach of the application of $\mathrm{HH}$ among the study sample. The data were analyzed using SPSS software, and descriptive statistics and logistic regression models were produced. A $P$-value less than 0.05 with $95 \%$ confidence interval was used to declare statistical significance.

Of 425 clinical study participants, 263 (61.9\%) were females, $169(39.8 \%)$ were at age group $31-39$ years, and $215(50.6 \%)$ were nurses/laboratory specialist, and 281 $(33.9 \%)$ were from departments of high risk of contamination. Overall, the average knowledge score was $75 \%$. However, there were significant higher scores in knowledge level among nurse and laboratory specialist had than the rest $(P<0.01)$ and three times likely more positive practice of hand hygiene in comparison to others [Adjusted Odds Ratio $(A O R)=3.285,95 \% \mathrm{Cl}, 1.764-6.116]$.
\end{abstract}

Health care workers in this study showed a good score of hand hygiene knowledge but suboptimal practices which could be addressed the need for multimodal training program on strict implementation of the guidelines and compliance with hand hygiene best practices.

\section{Keywords}

Hand hygiene, Health care workers, Hand rub, Knowledge, COVID-19

\begin{abstract}
Abbreviations
AOR: Adjusted Odds Ratio; HCAls: Healthcare-Associated Infections; HCWs: Health Care Workers; HH: Hand Hygiene; PHC: Primary Health Care; PSMMC: Prince Sultan Military Medical City
\end{abstract}

\section{Introduction}

It is well known that one of the International Patient Safety Goals (IPSGs) is reducing the risk of healthcare-associated infections (HCAls). However, HCAls are still a common serious problem in hospitals worldwide, resulting in several health risks to both patients and healthcare providers [1,2]. In this context, in 2009, the World Health Organization reported that the prevalence of HCAls in developed countries ranged between $5 \%$ and $15 \%$ of hospitalized patients. Another recent prevalence survey conducted in hospitals in several de- 
veloping countries showed that the prevalence of HCAls ranged between $14.8 \%$ and $19.1 \%$ [1,2].

It has been reported in many studies that compliance with hand hygiene protocols plays an important role in preventing and controlling HCAls. In this context, the WHO stated in the "Hand Hygiene Technical Reference Manual" that hand hygiene is the primary infection control measure and the most efficient and cost-effective strategy to reduce HCAls [3]. However, many observational studies and reports have shown that compliance with hand hygiene among healthcare providers is still very low in both developed and developing countries [4]. This low compliance and adherence with hand hygiene can be explained by several factors, such as overcrowding and lack of time, shortage in hand hygiene tools, irritation caused by hand hygiene products, lack of effective leadership and administrative support, and most importantly, lack of adequate knowledge, awareness, and positive attitude toward the best practices of hand hygiene [5].

Nowadays, the use of hand hygiene protocols has played a substantial role in decreasing the likelihood of infection transmission between health workers [6]. A meta-analysis conducted by J Kantor, showed that practicing proper hand washing found to be associated with a $24 \%$ reduction in COVID-19 viral transmission, suggesting that hand-to face contact may play a substantial role in infection transmission [7]. Likewise, other study showed the importance of empowering patients to promote hand hygiene practice among health workers [8]. Several international studies have reported that the overall average compliance rate of hand hygiene among healthcare providers worldwide is still low and less than $40 \%$, with rates being lower among physicians (32\%) than among nurses (48\%) [9]. Thus, it seems that lack of sufficient knowledge about hand hygiene guidelines and protocols have been reported to be a key reason for noncompliance $[2,5]$.

Assessment of the knowledge, attitude and practice (KAP) of hand hygiene within the health institution should be the first essential step to improve hand hygiene compliance [10], followed by introducing the enforcement of infection control policies, continued management support, direct observation, continued performance monitoring, availability of hand hygiene tools, continued hand hygiene training workshops and educational campaigns, which are all important aspects to sustain a high level of compliance $[11,12]$.

The Joint Commission (JC) states that the direct observation method is one of the most powerful methods to assess compliance with hand hygiene, and the Joint Commission expects hospitals to have a compliance of at least $90 \%$ with hand hygiene protocols [13]. Accordingly, in the year of 2017, the Infection Control Department in FCM performed daily direct observations of hand hygiene practices among all HCWs in all wards by assigning an Infection Control Nurse in each ward [2]. These findings indicate that the level of compliance with hand hygiene needs improvement since the data collected for the year 2017 showed insufficient compliance rates ranging from $60.8 \%$ to $94.7 \%$. In brief, since hand hygiene is considered to be the primary effective measure to prevent HCAls [14], the Family and Community Medicine Department at Prince Sultan Military Medical City should have a very high level of compliance with hand hygiene to prevent the spread of infectious diseases and to apply the essential level of safety required. This study will try to assess the level of knowledge, attitude and practice and identify the factors associated with the low compliance rate in order to provide local evidence to help in developing a process improvement project and sustaining a high level of hand hygiene practice.

To what extent were the HCWs knowledgeable enough with hand hygiene practices and what was their level of compliance with hand hygiene? Therefore, the aim of this study was to assess the knowledge, attitude and practice of hand hygiene among HCWs in primary health care centers at Prince Sultan Military Medical City, Riyadh, Saudi Arabia, as well as the motives and barriers associated with the low level of hand hygiene (HH) compliance with hand hygiene protocols in PHC centers.

\section{Methods}

\section{Study design and setting}

This is a hospital-based cross-sectional study, conducted in PHC centers at Prince Sultan Military Medical City (PSMMC), formerly known as Riyadh Military Hospital, which is one of the most advanced health care centers in the Middle East.

\section{Study subjects}

The study included clinical staff working at PHC centers, including physicians, nurses, emergency medical technicians and laboratory specialists. However, staff not in contact with patients, such as administrative staff, engineers and security were excluded.

\section{Sample size and sampling technique}

Findings from a previous study conducted at King Fahd Hospital of the University, Al-Khobar [15], Saudi Arabia, showed a mean hand hygiene compliance rate of $50.17 \%$ in a pre-intervention test among the hospital workers. Therefore, this prevalence was used to calculate the sample size of this study, at a $95 \%$ confidence interval and $\pm 5 \%$ margin of error. Thus, the sample size in this study would be 377 participants. We assumed that not all the participants could respond appropriately; hence, we increased the sample size by $12.5 \%$. Therefore, the final sample size was 425 participants. 
A proportional sampling from each $\mathrm{PHC}$ centers was conducted as 210 from Al Wazarat Health Center, 116 from Al Morooj, 37 from Al Oreja, 29 from Al Janoob, 25 from Al Manar, and 13 from Al Nadeem Health Center. In the other side for the application of the observation checklist a total of 109 participants were enrolled with proportional distribution to the capacity of each center.

\section{Data collection methods and instruments used}

A structured, self-administered questionnaire was distributed to the participants after they consented and agreed to participate in the study. An explanation about the study was provided to the participants, and each participant signed a written consent.

The survey instrument was based on the revalidated World Health Organization (WHO) designed questionnaire for this purpose and was used as a standard tool [16], with very minor modifications to adapt to the local context in Saudi Arabia. It consisted of four parts, which included standard questions to gather participant information, questions pertaining to knowledge of standard precautions, questions on compliance with standard precautions, and a general self-efficacy scale.

The self-administered questionnaire was piloted to test the validity and reliability of the questions, using $20 \mathrm{HCWs}$ from different local health settings and consequently changing the questions according to the needs.

In addition, a direct checklist was used to measure the adherence to the best practices in hand hygiene [17]. The checklist was based on that of the World Health Organization, which was used as a standard tool. For the hand hygiene observation protocol, $25 \%$ of the total sample was checked. Thus, it was considered as representative of the study cohort. Approximately 104 HCWs were included in this stage. However, the observation protocol randomly observed $30 \%$ of physicians, $10 \%$ of lab and paraclinics, $10 \%$ of emergency medical technicians and $50 \%$ of nurses, as they were the major group and had the most contact with patients. The researcher did the observation according to the WHO protocol. The compliance level was applied according to the WHO protocol score as compliant or non-compliant. Therefore, the term compliant is referred to a state of the performing all hand hygiene established movements, while the non-compliance is the missing of even one step in hand hygiene.

\section{Statistical analysis}

The data were cleaned, and the Statistical Package for Social Sciences (SPSS) version 20 (IBM, NY) was used for data analysis. A $P$-value lower than 0.05 was considered statistically significant. Descriptive statistics were carried out to illustrate means, standard deviations, and frequencies of the study variables. Both bivariate and multivariate logistic regression analyses were computed to identify variables having a significant association with
Table 1: Sociodemographic characteristics of the sample.

\begin{tabular}{|c|c|c|c|}
\hline Variables & Category & No. & $\%$ \\
\hline \multirow[t]{4}{*}{ Age } & $\leq 30$ years & 67 & 15.8 \\
\hline & $31-39$ years & 169 & 39.8 \\
\hline & 40-49 years & 112 & 26.4 \\
\hline & $\geq 50$ years & 77 & 18.1 \\
\hline \multirow[t]{2}{*}{ Sex } & Male & 162 & 38.1 \\
\hline & Female & 263 & 61.9 \\
\hline \multirow[t]{4}{*}{ Profession } & Nurse/lab specialist & 215 & 50.6 \\
\hline & Medical doctor/resident & 98 & 23.1 \\
\hline & Emergency medical & 31 & 7.3 \\
\hline & Technician/other & 81 & 19.1 \\
\hline \multirow{6}{*}{$\begin{array}{l}\text { Health care center } \\
\text { (HCC) }\end{array}$} & Al Wazarat & 206 & 48.5 \\
\hline & Al Morooj & 116 & 27.3 \\
\hline & Al Oreja & 36 & 8.5 \\
\hline & Al Janoob & 29 & 6.8 \\
\hline & Al Manar & 25 & 5.9 \\
\hline & Al Nadeem & 13 & 3.1 \\
\hline \multirow[t]{2}{*}{ Department } & Low contamination risk & 281 & 66.1 \\
\hline & High contamination risk & 144 & 33.9 \\
\hline
\end{tabular}

hand hygiene knowledge and compliance. Odds ratios with $95 \%$ confidence intervals were used to determine the strength of association between the dependent and independent variables.

\section{Results}

\section{Respondents' characteristics}

Of the 425 participants in this study, the mean age was 40.0 years \pm Standard Deviation (SD) 10.0 years, 263 (61.9\%) were females, and 215 (50.6\%) were nurses/ laboratory specialist, 206 (48.5\%) were from Alwazarat Health Care Center and 281 (66.1\%) were from low contamination risk department. Age was categorized into 4 subgroups: $\leq 30$ years $(15.8 \%), 31-39$ years $(39.8 \%)$, $40-49$ years $(26.4 \%)$, and $\geq 50$ years $(18.4 \%)$, as seen in Table 1 and Figure 1.

\section{Respondents' knowledge and attitude on hand hygiene}

On the other hand regarding received training activities on hand hygiene, around 1,322 (75.8\%) participants had received formal training in hand hygiene in the last 3 years, and 403 (94.8\%) participants routinely used an alcohol-based hand rub. For the calculation of the overall hand hygiene knowledge of the participants, seven domains composed of twenty-five questions were used. The correct answers from the questionnaire were given one point, whereas incorrect answers were given a score of zero. The maximum score achievable for knowledge was 35 points. The level of hand hygiene knowledge was calculated by dividing the responses into three 


$$
\begin{aligned}
& 100 \\
& 90 \\
& 80
\end{aligned}
$$

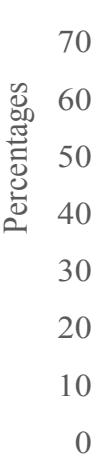

no

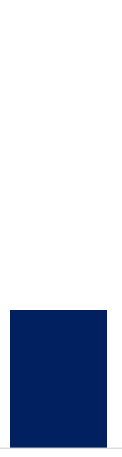

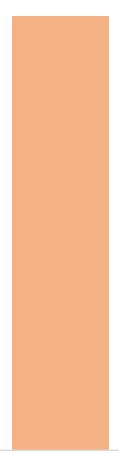

yes

Received formal training in hand hygiene

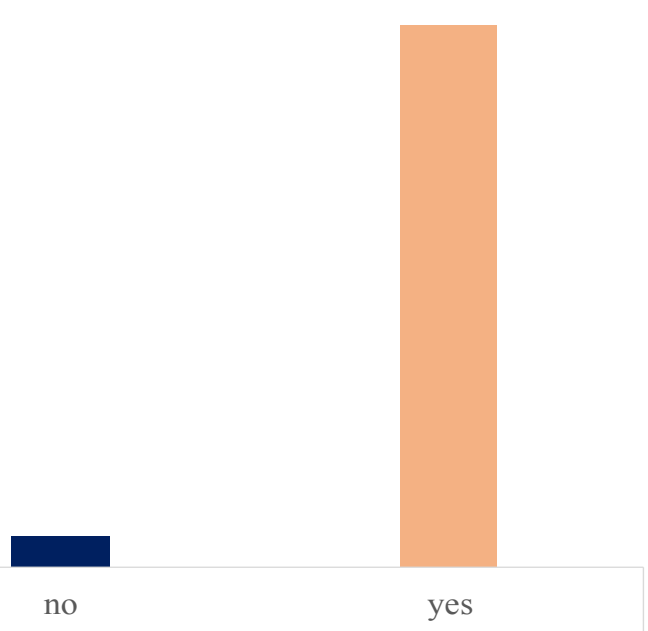

Routinely use an alcohol-based hand rub

Figure 1: Hand hygiene training rates and used of alcohol-based hand rub (last 3 years).

Method: In the left side of the figure showed the percentage of the health care workers those received training (yes) in the past on hand hygiene and those had not received (no). In the other side (right) of the figure, showed those health care workers routinely using an alcohol-based hand rubs (Yes) and those not used (no).

Results: The majority of the health care workers $(75.8 \%)$ had received formal training in hand hygiene in the last 3 years (yes). In the other side near almost all the (94.8\%) health care workers routinely used an alcohol-based hand rub (Yes).

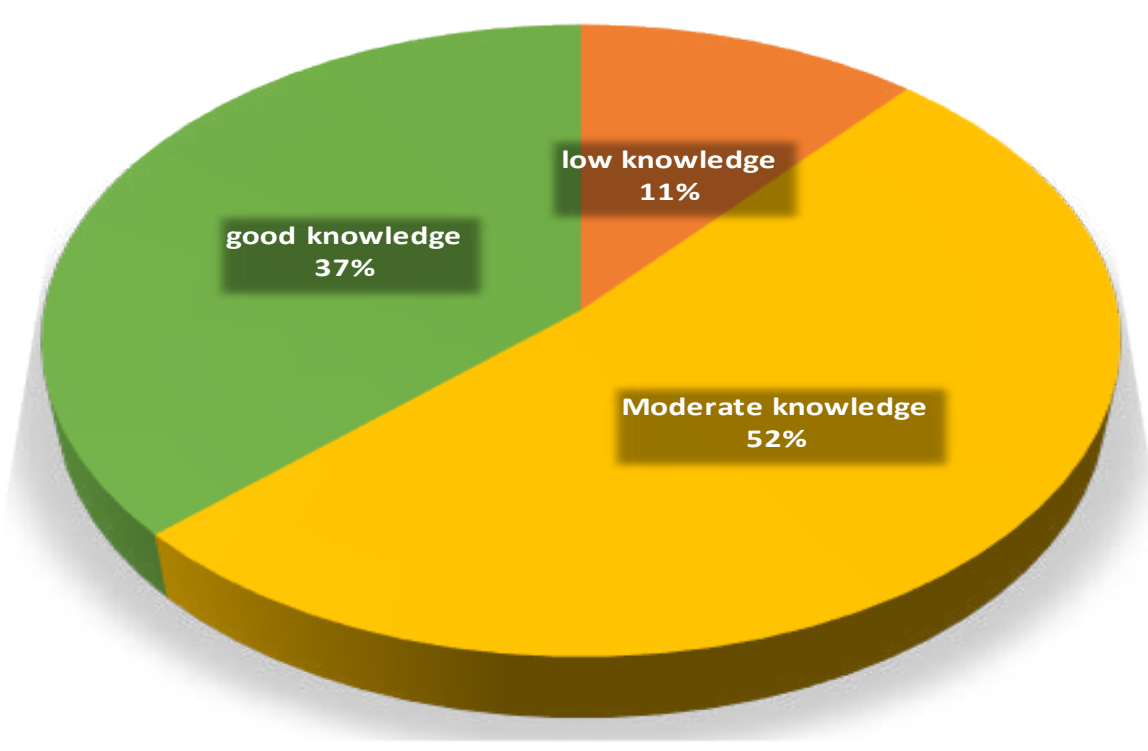

Figure 2: Level of hand hygiene knowledge among the participants.

Method: For the calculation of the overall hand hygiene knowledge of the participants, seven domains composed of twentyfive questions were used. The correct answers from the questionnaire were given one point, whereas incorrect answers were given a score of zero. The maximum score achievable for knowledge was 35 points. The level of hand hygiene knowledge was calculated by dividing the responses into three groups based on a score of more than $75 \%$ considered as adequate, $50-74 \%$ considered as moderate, and less than $50 \%$ considered as insufficient knowledge.

Results: Accordingly, 156 (36\%) participants were found to have adequate knowledge, 221 (52\%) participants had moderate knowledge (52\%), and the rest of the participants (11\%) had insufficient knowledge on hand hygiene.

groups based on a score of more than $75 \%$ considered as adequate, $50-74 \%$ considered as moderate, and less than $50 \%$ considered as insufficient knowledge. Accordingly, 156 (36\%) participants were found to have adequate knowledge, 221 (52\%) participants had moderate knowledge (52\%), and the rest of the participants (11\%) had insufficient knowledge on hand hygiene (Figure 2).

Regarding the main route of cross-transmission of germs, the majority, 186 (43.8\%) participants answered correctly that the "unclean hands of health care workers" was the main route, while, patients' exposure to colonized surfaces, Air circulating in the hospital, and Sharing noninvasive objects were answered $28.2 \%$, $17.9 \%$, and $10.1 \%$, respectively (Table 2 ).

Nevertheless, participants explained their opinions about the frequent source of germs responsible for 
Table 2: Correct answers on hand hygiene knowledge.

\begin{tabular}{|c|c|c|}
\hline Variables & No. & $\%$ \\
\hline \multicolumn{3}{|l|}{ Main route of cross-transmission of germs } \\
\hline Unclean hands of HCWs (True) & 186 & 43.8 \\
\hline Air circulating in the hospital & 76 & 17.9 \\
\hline Patients' exposure to colonized surfaces & 120 & 28.2 \\
\hline Sharing noninvasive objects & 43 & 10.1 \\
\hline \multicolumn{3}{|l|}{$\begin{array}{l}\text { Frequent source of germs responsible for } \\
\text { infections }\end{array}$} \\
\hline The hospital's water system & 49 & 11.5 \\
\hline The hospital's air & 64 & 15.1 \\
\hline Germs present on the patient (True) & 171 & 40.2 \\
\hline The hospital environment & 141 & 33.2 \\
\hline \multicolumn{3}{|l|}{$\begin{array}{l}\text { Hand hygiene actions preventing } \\
\text { transmission of germs to the patient }\end{array}$} \\
\hline Before touching a patient (True) & 400 & 94.1 \\
\hline $\begin{array}{l}\text { Immediately after a risk of body fluid exposure } \\
\text { (No) }\end{array}$ & 45 & 10.6 \\
\hline $\begin{array}{l}\text { After exposure to the immediate surroundings } \\
\text { of a patient (No) }\end{array}$ & 42 & 9.9 \\
\hline $\begin{array}{l}\text { Immediately before a clean/aseptic procedure } \\
\text { (True) }\end{array}$ & 394 & 92.7 \\
\hline \multicolumn{3}{|l|}{$\begin{array}{l}\text { Hygiene actions preventing transmission of } \\
\text { germs to the health-care worker }\end{array}$} \\
\hline After touching a patient & 383 & 90.1 \\
\hline $\begin{array}{l}\text { Immediately after a risk of body fluid exposure } \\
\text { [1] }\end{array}$ & 382 & 89.9 \\
\hline $\begin{array}{l}\text { Immediately before a clean/aseptic procedure } \\
\text { (No) }\end{array}$ & 51 & 12.0 \\
\hline $\begin{array}{l}\text { After exposure to the immediate surroundings } \\
\text { of a patient }\end{array}$ & 385 & 90.6 \\
\hline \multicolumn{3}{|l|}{$\begin{array}{l}\text { Alcohol-based hand rub and handwashing } \\
\text { with soap and water are true }\end{array}$} \\
\hline $\begin{array}{l}\text { Hand rubbing is more rapid for hand cleansing } \\
\text { than handwashing (True) }\end{array}$ & 305 & 72.1 \\
\hline $\begin{array}{l}\text { Hand rubbing causes skin dryness more than } \\
\text { handwashing (False) }\end{array}$ & 160 & 37.7 \\
\hline $\begin{array}{l}\text { Hand rubbing is more effective against germs } \\
\text { than handwashing (True) }\end{array}$ & 190 & 44.7 \\
\hline $\begin{array}{l}\text { Sequence performed in handwashing and hand } \\
\text { rubbing (False) }\end{array}$ & 229 & 54.0 \\
\hline $\begin{array}{l}\text { Minimum time for alcohol-based hand hygiene } \\
\text { to kill germs on hands (True) }\end{array}$ & 241 & 56.7 \\
\hline \multicolumn{3}{|l|}{$\begin{array}{l}\text { Which type of hand hygiene method is } \\
\text { required in the following situations? }\end{array}$} \\
\hline Before palpation of the abdomen (Rubbing) & 230 & 54.1 \\
\hline Before giving an injection (Rubbing) & 226 & 53.2 \\
\hline After emptying a bedpan (Rubbing) & 175 & 41.2 \\
\hline After removing examination gloves & 198 & 46.6 \\
\hline After making a patient's bed (Rubbing) & 201 & 47.3 \\
\hline After visible exposure to blood & 233 & 54.8 \\
\hline $\begin{array}{l}\text { Which of the following should be avoided, } \\
\text { as they are associated with an increased } \\
\text { likelihood of colonization of hands with } \\
\text { harmful germs? }\end{array}$ & & \\
\hline
\end{tabular}

\begin{tabular}{|l|l|l|}
\hline Wearing jewelry [1] & 374 & 88.0 \\
\hline Damaged skin [1] & 366 & 86.1 \\
\hline Artificial fingernails [1] & 358 & 84.2 \\
\hline Regular use of a hand cream (No) & 122 & 28.7 \\
\hline
\end{tabular}

Table 3: Healthcare-associated infection.

\begin{tabular}{|l|l|l|l|}
\hline Variables & Category & No. & $\%$ \\
\hline $\begin{array}{l}\text { Impact of a health care- } \\
\text { associated infection on a } \\
\text { patient's clinical outcome }\end{array}$ & Very low & 13 & 3.1 \\
\cline { 2 - 4 } & Low & 51 & 12.0 \\
\cline { 2 - 4 } & High & 259 & 60.9 \\
\cline { 2 - 4 } & Very high & 102 & 24.0 \\
\hline \multirow{2}{*}{$\begin{array}{l}\text { What is the effectiveness of } \\
\text { hand hygiene in preventing } \\
\text { health care-associated } \\
\text { infection? }\end{array}$} & Very low & 9 & 2.1 \\
\cline { 2 - 4 } & Low & 55 & 12.9 \\
\hline \multirow{2}{*}{$\begin{array}{l}\text { Among all patient safety } \\
\text { issues, how important } \\
\text { is hand hygiene at your } \\
\text { institution? }\end{array}$} & High & 235 & 55.3 \\
\hline \multirow{2}{*}{\begin{tabular}{l} 
Very high \\
\cline { 2 - 4 }
\end{tabular}} & Vow low & 126 & 29.6 \\
\hline & High & 119 & 28.0 \\
\hline & Very high & 191 & 44.9 \\
\hline
\end{tabular}

infections. A total of 171 (40.2\%) participants indicated correctly that germs present on the patient were frequently responsible for infections, as seen in Table 2. Similarly, most of the participants agreed that hand hygiene actions should be carried out before touching a patient and immediately before a clean/aseptic procedure, as the only methods to prevent transmission of germs (94.1\% and $92.7 \%$, respectively). It is likely, the participants' knowledge on the role of hand hygiene actions should be practiced after touching a patient (90.1\%), immediately after a risk of body fluid exposure (89.9\%), and after exposure to the immediate surroundings of a patient $(90.6 \%)$.

The majority of the HCWs $(72.1 \%)$ indicated that they prefer hand rubbing as more rapid for hand cleansing than handwashing, therefore they scored low level of response with regard to the effectiveness of hand rubbing versus handwashing against germs. The results of hand rubbing causing skin dryness, the sequence of handwashing and hand rubbing performances, and the indication of the accurate minimum time required for alcohol-based hand hygiene to kill most germs on hands were $44.7 \%, 37.7 \%, 54.0 \%$, and $56.7 \%$, respectively. When looking for the findings related to the type of hand hygiene method required according to the patient care situation, accurate responses ranged from washing is required after visible exposure to blood (54.8\%) to rubbing is required after emptying a bedpan (41.2\%).

With regards to the procedures and conditions that should be avoided by health care workers, as they are associated with an increased likelihood of colonization of the hands with harmful germs, $28.7 \%$ of participants indicated that the regular use of a hand cream was not 
considered among the avoidable materials; however, the majority responded accurately with regard to the wearing of jewelry $(88.0 \%)$ and avoiding rubbing with damaged skin or artificial fingernails $(86.1 \%$ and $84.2 \%$, respectively) (Table 2 ).

As shown in Table 3, the high impact of healthcare-associated infections on a patient's clinical outcome (60.9\%) and the effectiveness of hand hygiene in preventing healthcare-associated infections (55.3\%) were found dominant in this domain. On the other hand, the importance of hand hygiene at the study institution was found to range between a low of $28.0 \%$ and a high of $44.9 \%$.

The study analyzed the data on the correlation between sociodemographic features and the level of hand hygiene knowledge, as shown in Table 4. It was found that the profession of nurse/lab specialist proved to significantly determine the level of knowledge of hand hy-

Table 4: Level of knowledge on hand hygiene according to sociodemographic characteristics.

\begin{tabular}{|c|c|c|c|c|c|c|c|c|}
\hline \multirow[b]{2}{*}{ Variables } & \multirow[b]{2}{*}{ Category } & \multicolumn{2}{|l|}{ Low } & \multicolumn{2}{|c|}{ Moderate } & \multicolumn{2}{|c|}{ High } & \multirow[t]{2}{*}{$P$ value } \\
\hline & & No. & $\%$ & No. & $\%$ & No. & $\%$ & \\
\hline \multirow[t]{4}{*}{ Age } & $\leq 30$ years & 4 & 8.3 & 42 & 19.0 & 21 & 13.5 & \multirow[t]{4}{*}{0.119} \\
\hline & $31-39$ years & 17 & 35.4 & 79 & 35.7 & 73 & 46.8 & \\
\hline & $40-49$ years & 14 & 29.2 & 59 & 26.7 & 39 & 25.0 & \\
\hline & $\geq 50$ years & 13 & 27.1 & 41 & 18.6 & 23 & 14.7 & \\
\hline \multirow[t]{2}{*}{ Gender } & Male & 18 & 37.5 & 84 & 38.0 & 60 & 38.5 & \multirow[t]{2}{*}{0.992} \\
\hline & Female & 30 & 62.5 & 137 & 62.0 & 96 & 61.5 & \\
\hline \multirow[t]{4}{*}{ Profession } & Nurse/lab specialist & 16 & 33.3 & 109 & 49.3 & 90 & 57.7 & \multirow[t]{4}{*}{0.001} \\
\hline & Medical doctor/resident & 8 & 16.7 & 52 & 23.5 & 38 & 24.4 & \\
\hline & Emergency Medical & 1 & 2.1 & 16 & 7.2 & 14 & 9.0 & \\
\hline & Technician/others & 23 & 47.9 & 44 & 19.9 & 14 & 9.0 & \\
\hline \multirow[t]{6}{*}{ Health care center (HCC) } & Al Wazarat & 9 & 18.8 & 107 & 48.4 & 90 & 57.7 & \multirow[t]{6}{*}{0.001} \\
\hline & Al Morooj & 28 & 58.3 & 55 & 24.9 & 33 & 21.2 & \\
\hline & Al Oreja & 2 & 4.2 & 24 & 10.9 & 10 & 6.4 & \\
\hline & Al Janoob & 8 & 16.7 & 13 & 5.9 & 8 & 5.1 & \\
\hline & Al Manar & 1 & 2.1 & 15 & 6.8 & 9 & 5.8 & \\
\hline & Al Nadeem & 0 & 0.0 & 7 & 3.2 & 6 & 3.8 & \\
\hline \multirow[t]{2}{*}{ Department } & Low contamination risk & 31 & 64.6 & 140 & 63.3 & 110 & 70.5 & \multirow[t]{2}{*}{0.341} \\
\hline & High contamination risk & 17 & 35.4 & 81 & 36.7 & 46 & 29.5 & \\
\hline
\end{tabular}

Table 5: Logistic regression of the positive knowledge of hand hygiene and characteristics of the participants.

\begin{tabular}{|c|c|c|c|c|c|c|c|}
\hline Variables & Category & OR & $95 \% \mathrm{Cl}$ & p-value & AOR & $95 \% \mathrm{Cl}$ & P value \\
\hline \multirow[t]{4}{*}{ Age } & $\leq 30$ years & 0.874 & $0.416-1.835$ & 0.722 & - & - & - \\
\hline & 31-39 years & 1.481 & $0.812-2.704$ & 0.201 & - & - & - \\
\hline & $40-49$ years & 1.285 & $0.671-2.460$ & 0.449 & - & - & - \\
\hline & $\geq 50$ years & $\mathrm{R}$ & - & - & - & - & - \\
\hline \multirow[t]{2}{*}{ Sex } & Male & 1.032 & $0.653-1.631$ & 0.894 & - & - & - \\
\hline & Female & $\mathrm{R}$ & - & - & - & - & - \\
\hline \multirow[t]{4}{*}{ Profession } & Nurse/lab specialist & 3.178 & $1.640-6.159$ & 0.001 & 3.467 & $1.829-6.571$ & 0.001 \\
\hline & Medical doctor/resident & 2.375 & $1.134-4.972$ & 0.022 & 2.569 & $1.246-5.300$ & 0.011 \\
\hline & Emergency medical & 5.167 & $1.882-14.183$ & 0.001 & 5.179 & $1.972-13.600$ & 0.001 \\
\hline & Technician/others & $\mathrm{R}$ & - & - & $\mathrm{R}$ & - & - \\
\hline \multirow[t]{6}{*}{ Health care center } & Al Wazarat & 0.954 & 0.299-3.048 & 0.937 & - & - & - \\
\hline & Al Morooj & 0.563 & $0.171-1.859$ & 0.346 & - & - & - \\
\hline & Al Oreja & 0.448 & 0.116-1.722 & 0.242 & - & - & - \\
\hline & Al Janoob & 0.583 & $0.143-2.372$ & 0.451 & - & - & - \\
\hline & Al Manar & 0.716 & $0.178-2.886$ & 0.639 & - & - & - \\
\hline & Al Nadeem & $\mathrm{R}$ & - & - & - & - & - \\
\hline \multirow[t]{2}{*}{ Department } & Low contamination risk & 1.548 & $0.879-2.728$ & 0.131 & - & - & - \\
\hline & High contamination risk & $\mathrm{R}$ & - & - & - & - & - \\
\hline
\end{tabular}


giene, with a $P$-value of $<0.001$. Also, Al Wazarat Health Center showed a statistically significant result of the knowledge level on hand hygiene, with a $P$-value of $<$ 0.001 . However, the study found a lack of association between hand hygiene knowledge level and some sociodemographic features, such as age, gender and department, with resulting $P$-values $<0.05$. Level of knowledge of hand hygiene also proved to vary with gender, as females were more knowledgeable on hand hygiene (over $60 \%$ ) compared with males. It was also associated with age between $31-39$ years $(46.8 \%)$ compared with other age ranges.

\section{Associated factors with level of knowledge and at- titude of hand hygiene}

Both bivariate and multivariate logistic regression analyses were applied for the assessment of the sociodemographic factors and the positive level of knowledge in the participants. Significant differences were found between the different categories of professionals (adjusted odds ratios) and clear likelihood of positive knowledge on hand hygiene practice was found among nurses, medical doctors, and emergency medical staff in comparison to the reference (technician/others), as shown in Table 5. The rest of the factors did not show any significant differences.

Logistic regression of the positive practice of hand hygiene and characteristics of the participants are shown in Table 6. The study found positive correlations between the positive practice of hand hygiene and the professions, while there was no positive logistic regression between the positive practice of hand hygiene and

Table 6: Logistic regression of the positive practice of hand hygiene and characteristics of the participants.

\begin{tabular}{|c|c|c|c|c|c|c|c|}
\hline Variables & Category & OR & $95 \% \mathrm{Cl}$ & $P$ value & AOR & $95 \% \mathrm{Cl}$ & $P$ value \\
\hline \multirow[t]{4}{*}{ Age } & $\leq 30$ years & 0.674 & $0.331-1.373$ & 0.277 & - & - & - \\
\hline & 31-39 years & 0.718 & $0.400-1.289$ & 0.267 & - & - & - \\
\hline & $40-49$ years & 0.983 & $0.528-1.830$ & 0.956 & - & - & - \\
\hline & $\geq 50$ years & $\mathrm{R}$ & - & - & - & - & - \\
\hline \multirow[t]{2}{*}{ Sex } & Male & 0.823 & $0.522-1.298$ & 0.402 & - & - & - \\
\hline & Female & $\mathrm{R}$ & - & - & - & - & - \\
\hline \multirow[t]{4}{*}{ Profession } & Nurse/lab specialist & 3.492 & $1.849-6.594$ & 0.000 & 3.285 & $1.764-6.116$ & 0.001 \\
\hline & Medical doctor/resident & 2.313 & $1.125-4.753$ & 0.023 & 2.306 & $1.149-4.625$ & 0.019 \\
\hline & Emergency medical & 3.138 & 1.149- 8.569 & 0.026 & 2.436 & $0.958-6.193$ & 0.061 \\
\hline & Technician/others & $\mathrm{R}$ & - & - & $\mathrm{R}$ & - & - \\
\hline \multirow[t]{6}{*}{ Health care center } & Al Wazarat & 2.036 & $0.590-7.030$ & 0.261 & 2.184 & $0.638-7.472$ & 0.213 \\
\hline & Al Morooj & 1.036 & $0.291-3.689$ & 0.956 & 1.126 & 0.318-3.982 & 0.854 \\
\hline & Al Oreja & 1.113 & $0.278-4.466$ & 0.879 & 1.228 & $0.309-4.878$ & 0.771 \\
\hline & Al Janoob & 0.948 & $0.218-4.128$ & 0.943 & 1.000 & $0.233-4.291$ & 1.000 \\
\hline & Al Manar & 0.876 & $0.197-3.903$ & 0.863 & 0.908 & $0.205-4.014$ & 0.899 \\
\hline & Al Nadeem & $\mathrm{R}$ & - & - & $\mathrm{R}$ & - & - \\
\hline \multirow[t]{2}{*}{ Department } & Low contamination risk & 1.239 & $0.744-2.064$ & 0.410 & - & - & - \\
\hline & High contamination risk & $\mathrm{R}$ & - & - & - & - & - \\
\hline
\end{tabular}

Table 7: Hand hygiene attitude among the study participants.

\begin{tabular}{|c|c|c|c|c|c|c|}
\hline \multirow[b]{3}{*}{ Variables } & \multirow[b]{3}{*}{ Category } & \multicolumn{5}{|c|}{ Attitude level } \\
\hline & & \multicolumn{2}{|c|}{ Poor } & \multicolumn{2}{|c|}{ Good } & \multirow[b]{2}{*}{$P$ value } \\
\hline & & No. & $\%$ & No. & $\%$ & \\
\hline \multirow[t]{4}{*}{ Age } & $\leq 30$ years & 53 & 15.5 & 14 & 16.9 & 0.927 \\
\hline & $31-39$ years & 135 & 39.5 & 34 & 41.0 & \\
\hline & $40-49$ years & 90 & 26.3 & 22 & 26.5 & \\
\hline & $\geq 50$ years & 64 & 18.7 & 13 & 15.7 & \\
\hline \multirow[t]{2}{*}{ Sex } & Male & 144 & 42.1 & 18 & 21.7 & 0.001 \\
\hline & Female & 198 & 57.9 & 65 & 78.3 & \\
\hline Profession & Nurse/lab specialist & 157 & 45.9 & 58 & 69.9 & 0.001 \\
\hline
\end{tabular}




\begin{tabular}{|l|l|l|l|l|l|l|}
\hline & Medical doctor/resident & 83 & 24.3 & 15 & 18.1 \\
\hline & Emergency medical & 27 & 7.9 & 4 & 4.8 \\
\hline & Technician/others & 75 & 21.9 & 6 & 7.2 \\
\hline Health care center (HCC) & Al Wazarat & 141 & 41.2 & 65 & 78.3 & 0.001 \\
\hline & Al Morooj & 108 & 31.6 & 8 & 9.6 & 7.2 \\
\hline & Al Oreja & 30 & 8.8 & 6 & 1.2 & \\
\hline & Al Janoob & 28 & 8.2 & 1 & 2.4 & \\
\hline & Al Manar & 23 & 6.7 & 2 & 1.2 & \\
\hline & Al Nadeem & 12 & 3.5 & 1 & 72.3 & 0.185 \\
\hline & Low contamination risk & 221 & 64.6 & 60 & 27.7 \\
\hline
\end{tabular}

Table 8: Hand hygiene positive practice among the study participants.

\begin{tabular}{|c|c|c|c|c|c|c|}
\hline \multirow[b]{3}{*}{ Variables } & \multirow[b]{3}{*}{ Category } & \multicolumn{5}{|c|}{ Practice Level } \\
\hline & & \multicolumn{2}{|l|}{ Low } & \multicolumn{2}{|c|}{ High } & \multirow[t]{2}{*}{$P$ value } \\
\hline & & No. & $\%$ & No. & $\%$ & \\
\hline \multirow[t]{4}{*}{ Age } & $\leq 30$ years & 42 & 16.3 & 25 & 14.9 & 0.959 \\
\hline & $31-39$ years & 103 & 40.1 & 66 & 39.3 & \\
\hline & $40-49$ years & 67 & 26.1 & 45 & 26.8 & \\
\hline & $\geq 50$ years & 45 & 17.5 & 32 & 19.0 & \\
\hline \multirow[t]{2}{*}{ Sex } & Male & 106 & 41.2 & 56 & 33.3 & 0.101 \\
\hline & Female & 151 & 58.8 & 112 & 66.7 & \\
\hline \multirow[t]{4}{*}{ Profession } & Nurse/lab specialist & 113 & 44.0 & 102 & 60.7 & 0.001 \\
\hline & Medical doctor/resident & 59 & 23.0 & 39 & 23.2 & \\
\hline & Emergency medical & 20 & 7.8 & 11 & 6.5 & \\
\hline & Technician/others & 65 & 25.3 & 16 & 9.5 & \\
\hline \multirow[t]{6}{*}{ Health care center (HCC) } & Al Wazarat & 105 & 40.9 & 101 & 60.1 & 0.008 \\
\hline & Al Morooj & 81 & 31.5 & 35 & 20.8 & \\
\hline & Al Oreja & 23 & 8.9 & 13 & 7.7 & \\
\hline & Al Janoob & 21 & 8.2 & 8 & 4.8 & \\
\hline & Al Manar & 18 & 7.0 & 7 & 4.2 & \\
\hline & Al Nadeem & 9 & 3.5 & 4 & 2.4 & \\
\hline \multirow[t]{2}{*}{ Department } & Low contamination risk & 164 & 63.8 & 117 & 69.6 & 0.214 \\
\hline & High contamination risk & 93 & 36.2 & 51 & 30.4 & \\
\hline
\end{tabular}

Table 9: Comparison of observed five moments of hand hygiene among HCWs in different PHC centers.

\begin{tabular}{|l|l|l|l|l|}
\hline Centers & Number of HCWs & Opportunities & Action & Compliance (\%) \\
\hline Al Oreja Health Center & 9 & 45 & 44 & 97.0 \\
\hline Al Janoob Health Center & 7 & 35 & 33 & 94.0 \\
\hline Al Nadeem Health Center & 3 & 15 & 14 & 93.0 \\
\hline Al Wazarat Health Center & 52 & 155 & 144 & 92.0 \\
\hline Al Manar Health Center & 6 & 30 & 24 & 80.0 \\
\hline Al Morooj Health Center & 32 & 80 & 56 & 70.0 \\
\hline Total & 109 & 360 & 315 & 87.5 \\
\hline
\end{tabular}

age, gender, healthcare center, or department. Being a nurse/lab specialist $(\mathrm{AOR}=3.285,95 \% \mathrm{Cl}, 1.764-6.116$, $P$-value $=0.001)$ tended to increase the odds of positive practice of hand hygiene by 3 times, while the odds of positive practice of hand hygiene tended to increase by 2 times in both medical doctor/resident and emergency medical categories $(A O R=2.306,95 \% \mathrm{Cl}, 1.149-4.625$, $P$-value $=0.019$ and $A O R=2.436,95 \% \mathrm{Cl}, 0.958-6.193$, $P$-value $=0.061$, respectively) .

The study analyzed the data on hand hygiene attitude among the study participants, as shown in Table 7. It found that being male proved to significantly de- 
termine the level of attitude of hand hygiene, with a $P$-value of 0.001 . Also, the nurses showed a statistically significant result with regard to the attitude level of hand hygiene, with a $P$-value of 0.001 . Additionally, Al Wazarat Health Center showed a statistically significant result with regard to the attitude level of hand hygiene, with a $P$-value of 0.0001 .

Table 8 shows that the level of hand hygiene positive practice among the participants. The chi-square tests of the level of hand hygiene positive practice showed significant differences in professions and health care centers, where nurses and the Al Wazarat Health Center were found to have a high level of practice.

Table 9 shows the observed compliance of five moments of hand hygiene among HCWs in different PHC centers. The evaluation revealed the highest compliance rate (97\%) at the Al Oreja Health Center; however, the Al Janoob, Al Nadeem andAI Wazarat Health Centers had compliance rates from $92 \%$ to $94 \%$, with the $\mathrm{Al}$ Mannar and Al Morooj Health Centers having the lowest compliance rates ( $80 \%$ and $70 \%$, respectively).

\section{Discussion}

Our 425 total participants were from a relatively young population, with a mean age of $40 \pm 10$ years, and most of them were between the ages of 31 and 39 years. However, age group could be varying from one study to other as shown in a study conducted among Saudi HCWs in Arar (20 and 39 years) [3], or in Al-Qas$\operatorname{sim}$ (20 and 59 years) [18], as well as in Karad (19 and 25 years) [19]. Similarly, reported in African country (Nigeria) with a range of respondents between the ages of 20 and 29 years [20]. This variation in age group between different studies locally and internationally, could be explained by some authors as an indirect reflection of the level of adherence to hand hygiene. As age of the HCW (physicians or nurses) can be used as deceptive in regards to the number of years of practice, thus studied concluded that age and experience probably were positively correlated with adherence of $\mathrm{HH}$ [21].

In our findings, wearing jewelry was the main source of infection. It was similar to another study in Arar, Saudi Arabia, which found wearing jewelry and accessories were the main source of infection [3]. In our study, the role of hand hygiene actions in preventing the transmission of germs to the patient should be carried before touching the patient, which was the primary method to prevent infections. Another study from India found that $85 \%$ of participants knew that hand hygiene actions before touching a patient could prevent transmission of germs [22]. It was similar to another study in Jeddah, Saudi Arabia, carried out by Mohidin S, et al., which found hand hygiene practices should be carried out before touching the patient and his/her surrounding environment [5].

With the recent pandemic of COVID-19, the impor- tance of hand hygiene is vital now more than ever in playing a significant role in preventing the spread of the infectious disease. In our study, $75.8 \%$ of participants had received formal training in hand hygiene and $94.8 \%$ routinely used an alcohol-based hand rub, which differed from another study in Ain Shams, Egypt, where 3.9\% of participants used an antiseptic hand wash [23]. In our study, when analyzing the participants' level of attitude toward hand hygiene, our finding found that hand rubbing was more rapid than handwashing. A study in Jeddah, Saudi Arabia, found that most health care workers used alcohol and handwashing with water before touching the patient and handwashing with water more than alcohol after touching the patient [5]. Additionally, it differed from another study in Nepal carried out by Yadav SK, et al. that found that health care workers mostly used alcohol-based hand rubs [24]. It differed from another study in Al-Qassim, Saudi Arabia, that found soap and water were the most common agents for cleansing the hands of HCWs [18]. In our study, the main route of cross-contamination of germs was the unclean hands of HCWs (43.8\%). It differed from another study in Arar, Saudi Arabia, carried out by Rawan D, et al. that found the main route of transmission of germs was bathrooms in hospitals [3]. Unlikely, our results were not agreed with findings from another study in Nepal carried out by Yadav SK, et al. that found that the hands of health care workers were the most common mode of transmission of pathogens to patients. Moreover, a study in India found $31 \%$ of participants reported that the main route of cross-transmission was the unclean hands of healthcare workers [22].

Center for Disease Control and Prevention has emphasized on the critical role of direct and indirect spread of coronaviruses (COVID-19) between Health care personnel while they are handling and supporting patients during the outbreak [25]. In our study, nurses, lab specialists, medical doctors, residents, emergency medical personnel and technicians had different rates of hand hygiene knowledge, with nurses having the highest knowledge (57.7\%) compared to the other professions. The same results were found in another study carried by KM Abdalaziz, et al. in Ain Shams, Egypt, where they found the knowledge score was higher among nurses than other health care workers [23].

It differed from another study in Arar, Saudi Arabia, carried out by Rawan D, et al., where they found that both nurses and physicians had almost the same rated knowledge [3]. Additionally, it differed from another study in Karad, carried out by Mahado B, et al., where they found nursing students had better knowledge than nursing staff, and the health care workers there had moderate knowledge on handwashing [19]. A similar study was done in Al-Qassim, Saudi Arabia, carried by out by Badria A, et al., where they found HCWs had low knowledge of hand hygiene [18]. It differed from another study in Pakistan carried out by Sajida Pameen, et al. 
who found $42.2 \%$ of all participants were well-qualified and knowledgeable about hand hygiene. This study showed that hospital staff needed to be educated on the practical and cost-effective benefits of hand hygiene [26]. It differed from a study in Kenya carried out by Hannah $\mathrm{M}$, who found half of the respondents had poor knowledge of hand hygiene [27]. It differed from a study in India carried out by Krwatrth $R$, et al., who found that $76 \%$ of participants had moderate knowledge of hand hygiene [22].

Our findings were inconsistent with other study in Nepal carried out by Yadav SK, et al. that found only $9 \%$ of participants had good knowledge on hand hygiene, which proved that their health care workers had moderate knowledge on hand hygiene [24]. Another study in Vietnam carried out by Cam Dung, et al. found that health care workers had good knowledge of hand hygiene [28].

We are referring to the importance of hand hygiene to prevent and control infection in health among health care workers institution which applied to COVID-19. As we are in the Era of COVID-19, the strict implication of hand hygiene is of paramount consideration in the prevention of the infections, including COVID-19. Recently, global reports described that, hand hygiene campaign for the fight against COVID-19 is crucial to stop the spread of COVID-19 virus as it primarily spreads through droplet and contact transmission [29]. In addition, such research will be great helpful for the $\mathrm{MOH}$ in Saudi Arabia for example to develop guidance on COVID-19 surveillance in healthcare and community settings [30].

In our study, the WHO protocol score [2], was used to measured compliance level of the HCWs in the PHC centers during the observational sessions. Our findings revealed $87.5 \%$ of compliance level; however, variation between PHC centers was not statistically significant. Findings from a study assessing the compliance of $\mathrm{HH}$ in Qatar, has reported to our study (90\%) [31], while other studies from Indonesia and Ethiopia showed very low compliance rate $(27.1 \%$ and $14.9 \%$, respectively) [32,33].

Eventually, low hand hygiene compliance levels are still a disquieting challenge worldwide despite the numerous interventions and campaigns performed in promoting this action. Nowadays, hand hygiene is particularly critical for frontline HCWs, who are overstretched for the response to the COVID-19 pandemic, where strict hand hygiene compliance by everyone is required and not exclusive to HCWs but include any person to avoid the infection. Recently, WHO launched the Worldwide campaign called "\#SafeHands Challenge" with the aim to reducing hand recontamination and therefore, infection prevention [34], as well as to ensuring patient and HCW safety at all times as an important key during this pandemic [30].

Although $\mathrm{HH}$ procedures are relatively simple, stud- ies have shown that the compliance among healthcare workers is not favorable. Some authors revealed the main barriers in the compliance of $\mathrm{HH}$ include lack of education, lack of persuasion, high work load, working status, lack of techniques, poor quality of implemented method, and guidelines [35-37]. Moreover, some studies illustrated that educating the patients about the important of the hand hygiene, help in the compliance of the health care worker in applying hand hygiene [8]. Our findings revealed that more than $75.8 \%$ of the participants had a set for training on hand hygiene in the past three years. Though, exposure of the health care workers to training practice of hand hygiene can enhance significantly their contribution to their good practices $[3,38]$.

\section{Limitation}

However, the study findings should be viewed in light of some limitations. This is a cross-sectional survey, which, by design, does not take into account the possible changes in knowledge and compliance of the same cohort of students across time. Other limitations are the use of self-reported responses on the practice of hand hygiene. Although self-reporting is the easiest way to collect data, bias can be introduced as respondents may report better practice than their actual practice. However, the investigator used an observational method in a representative sample to reflect the actual practice of hand hygiene among the health care workers.

\section{Conclusion}

In conclusion, health care workers in this study showed a good score of hand hygiene knowledge but suboptimal practices which could be addressed the need for multimodal training program on strict implementation of the guidelines and compliance with hand hygiene best practices. The study also showed that the participants had been trained on handwashing before, touching patients and after dealing with patients to prevent the transmission of diseases from one patient to another and to reduce infection.

\section{Declarations}

\section{Conflict of interest}

The authors declare they have no conflicts of interest.

\section{Sources of funding}

None.

\section{Ethical approval}

This work received an IRB approved from the Research Ethic Committee at the Prince Sultan Medical City (\#HP-01-R079) and from King Abdulla International Medical Research Center at the Minestry of National Guard for Health Affair in Riyadh (\#SP19/055/R). 


\section{References}

1. World Health Organization, WHO Patient Safety (2009)? Hand hygiene technical reference manual: To be used by health-care workers, trainers and observers of hand hygiene practices.

2. World Health Organization (2009) WHO guidelines on hand hygiene in health care.

3. Aledeilah RDI, El-Fetoh NMA, Albaker AF, Aljabbab AA, Alkhannani SJ, et al. (2018) Assessment of knowledge, attitude and practice of hand hygiene among health care workers in Arar City, Saudi Arabia. The Egyptian Journal of Hospital Medicine 70: 491-498.

4. World Health Organization (2009) World health statistics 2009.

5. Pittet D, Hugonnet $S$, Harbarth $S$, Mourouga P, Sauvan V, et al. (2000) Effectiveness of a hospital-wide programme to improve compliance with hand hygiene. Infection Control Programme. Lancet 356: 1307-1312.

6. Kantor J (2020) Behavioral considerations and impact on personal protective equipment use: Early lessons from the coronavirus (COVID-19) pandemic. J Am Acad Dermatol 82: 1087-1088.

7. Nicas M, Best D (2008) A study quantifying the hand-toface contact rate and its potential application to predicting respiratory tract infection. J Occup Environ Hyg 5: 347-352.

8. Awaji MA, Al-Surimi K (2016) Promoting the role of patients in improving hand hygiene compliance amongst health care workers. BMJ Qual Improv Rep 5.

9. Erasmus V, Daha TJ, Brug H, Richardus JH, Behrendt MD, et al. (2010) Systematic review of studies on compliance with hand hygiene guidelines in hospital care. Infect Control Hosp Epidemiol 31: 283-294.

10. Alfahan A, Alhabib S, Abdulmajeed I, Rahman S, Bamuhair S (2016) In the era of corona virus: Health care professionals' knowledge, attitudes, and practice of hand hygiene in Saudi primary care centers: A cross-sectional study. J Community Hosp Intern Med Perspect 6: 32151.

11. Allegranzi B, Stewardson A, Pittet D (2012) Nationwide benchmarking of hand hygiene performance. Infect Control Hosp Epidemiol 33: 621-623.

12. Ashraf MS, Hussain SW, Agarwal N, Ashraf S, Gabriel EK, et al. (2010) Hand Hygiene in long-term care facilities: A multicenter study of knowledge, attitudes, practices, and barriers. Infect Control Hosp Epidemiol 31: 758-762.

13. Schmidt B (2011) Hand hygiene measurement and education: Compliance improvement can be successful, sustained, and cost effective. Patient Safety and Quality Healthcare, Illinois, USA.

14. Gichuhi AW, Kamau SM, Nyangena E, Otieno-Ayayo NZ (2015) Health care workers adherence to infection prevention practices and control measures: A case of a level four district hospital in Kenya. American Journal of Nursing Science 4: 39-44.

15. Al Kuwaiti A (2017) Impact of a multicomponent hand hygiene intervention strategy in reducing infection rates at a university hospital in Saudi Arabia. Interv Med Appl Sci 9: 137-143.

16. Thakker VS, Jadhav PR (2015) Knowledge of hand hygiene in undergraduate medical, dental, and nursing students: A cross-sectional survey. J Family Med Prim Care 4: 582-586.
17. Sax H, Allegranzi B, Chraïti MN, Boyce J, Larson E, et al. (2009) The World Health Organization hand hygiene observation method. Am J Infect Control 37: 827-834.

18. Al Ra'awji BA, Almogbel ES, Alharbi LA, Alotaibi AK, AI-Qazlan FA, et al. (2018) Knowledge, attitudes, and practices of health-care workers regarding hand hygiene guidelines in Al-Qassim, Saudi Arabia: A multicenter study. Int J Health Sci (Qassim) 12: 3-8.

19. Shinde MB, Mohite VR (2014) A study to assess knowledge, attitude and practices of five moments of hand hygiene among nursing staff and students at a tertiary care hospital at Karad. International Journal of Science and Research 3: 311-321.

20. Raimi MO, Omidiji AO, Funmilayo AA, Owobi OE (2018) A survey of hand washing behavior and awareness among health care workers in health care facilities in Kubwa District of Bwari Area Council, FCT Abuja, Nigeria. Annals of Ecology and Environmental Science 2: 14-31.

21. Ellingson K, Haas JP, Aiello AE, Kusek L, Maragakis LL, et al. (2014) Strategies to prevent healthcare-associated infections through hand hygiene. Infect Control Hosp Epidemiol 35: 937-960.

22. Brahmbhatt KR, Lodhiya KK (2019) Hand hygiene knowledge among undergraduate medical students in Junagadh, Gujarat, India. International Journal of Community Medicine and Public Health 6: 1917-1922.

23. Elaziz KMA, Bakr IM (2009) Assessment of knowledge, attitude and practice of hand washing among health care workers in Ain Shams University Hospitals in Cairo. J Prev Med Hyg 50: 19-25.

24. Yadav SK, Giri A (2018) Assessment of Hand Hygiene Knowledge among Residents and Nursing staffs at Nobel Medical College Teaching Hospital, Biratnagar. Journal of Nepal Paediatric Society 38: 69-73.

25. https://www.cdc.gov/coronavirus/2019-ncov/infection-control/hcp-hand-sanitizer.html

26. Parveen S, Saddiqa A, Inam H, Pervaiz F, Awan S, et al. (2019) Assessment of knowledge and compliance on hand hygiene among health care team in tertiary care centre. Pakistan Armed Forces Medical Journal 69: S346-S349.

27. Muiru HW (2018) Knowledge, attitude and barriers to hands hygiene practice: A study of Kampala International University undergraduate medical students. International Journal of Community Medicine and Public Health 5: 3782-3787.

28. Le CD, Lehman EB, Nguyen TH, Craig TJ (2019) Hand hygiene compliance study at a large central hospital in Vietnam. Int J Environ Res Public Health 16: 607.

29. Lotfinejad N, Peters A, Pittet D (2020) Hand hygiene and the novel coronavirus pandemic: The role of healthcare workers. J Hosp Infect.

30. Gon G, Dancer S, Dreibelbis R, Graham WJ, Kilpatrick C (2020) Reducing hand recontamination of healthcare workers during COVID-19. Infect Control Hosp Epidemiol.

31. Arias AV, Garcell HG, Ochoa YR, Arias KF, Miranda FR (2016) Assessment of hand hygiene techniques using the World Health Organization's six steps. J Infect Public Health 9: 366-369.

32. Santosaningsih D, Erikawati D, Santoso S, Noorhamdani N, Ratridewi I, et al. (2017) Intervening with healthcare workers' hand hygiene compliance, knowledge, and perception in a limited-resource hospital in Indonesia: A randomized controlled trial study. Antimicrob Resist Infect Control 6: 23. 
33. Engdaw GT, Gebrehiwot M, Andualem Z (2019) Hand hygiene compliance and associated factors among health care providers in Central Gondar zone public primary hospitals, Northwest Ethiopia. Antimicrob Resist Infect Control 8: 190.

34. World Health Organization (2020) Connecting the world to combat coronavirus / \#SafeHands Challenge.

35. Zakeri H, Ahmadi F, Rafeemanesh E, Saleh LA (2017) The knowledge of hand hygiene among the healthcare workers of two teaching hospitals in Mashhad. Electron Physician 9: 5159-5165.
36. Wisniewski MF, Kim S, Trick WE, Welbel SF, Weinstein RA, et al. (2007) Effect of education on hand hygiene beliefs and practices: A 5-Year program. Infect Control Hosp Epidemiol 28: 88-91.

37. Jemal S (2018) Knowledge and practices of hand washing among health professionals in Dubti Referral Hospital, Dubti, Afar, Northeast Ethiopia. Adv Prev Med.

38. Ekwere TA, Okafor IP (2013) Hand hygiene knowledge and practices among healthcare providers in a tertiary hospital, south west, Nigeria. Int J Infect Control 9. 